\title{
SISTEMAS DE REPUTACIÓN ONLINE (REPUTATIONAL FEEDBACK SYSTEMS), OPINIONES FALSAS Y COMPETENCIA DESLEAL
}

\author{
Aitor Mora ASTABURUAGA \\ ESTUDIANTE DEL MÁSTER EN ACCESO A LA ABOGACÍA \\ UNIVERSIDAD DE LA RIOJA \\ Jesús Aitor PRado SeOANE \\ ESTUdiANTE DEL MÁSTER EN ACCESo A LA ABOGACÍA \\ UNIVERSIDAD DE LA RIOJA
}

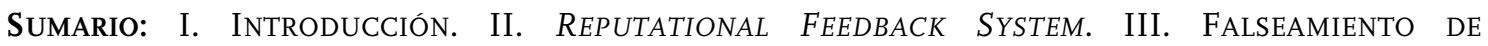
REPUTATIONAL FEEDBACK SYSTEM COMO ACTOS DE COMPETENCIA DESLEAL. IV. CONTROL DE LOS REPUTATIONAL FEEDBACK SYSTEMS. V. CONCLUSIONES. VI. BIBLIOGRAFÍA.

RESUMEN: Una de las cosas mas importantes a tener en cuenta antes de comprar un determinado producto, a través de plataformas de comercio electrónico, son las opiniones positivas de los demás clientes. Sin embargo, ¿son estas opiniones fiables? Este trabajo trata de analizar el funcionamiento de estos sistemas de reputación online (reputational feedback systems) y el efecto que tiene su falseamiento en el ámbito de la competencia desleal.

PAlABRAS ClAVE: comercio electrónico, competencia desleal, fake news; sistemas de reputación online, opiniones falsas, TripAdvisor.

\section{REPUTACIONAL FEEDBACK SYSTEMS, FAKE REVIEWS AND UNFAIR COMMERCIAL PRACTICES}

ABSTRACT: One of the most important things that we should consider when we want to contract throught e-commerce plataforms is the numbers of positive reviews that these product has before buying it. However, can we trust in those reviews? This study analyzes how this reputational feedback systems works and define the effect of these fake reviews in the case of the unfair commercial practices.

KEYWORDS: E-commerce, reputacional feedback system, fake reviews, TripAdvisor, unfair commercial practices.

\section{Introducción}

La economía actual se encuentra cada vez más orientada al mundo digital, de hecho, ya se puede realizar cualquier negocio jurídico a través de Internet, desde comprar cualquier 
cosa hasta contratar los servicios de profesionales. El comercio electrónico es una realidad que ha venido para quedarse y que está desplazando al comercio tradicional en muchos sectores.

Según los últimos datos publicados por la Comisión Nacional de los Mercados y la Competencia (a partir de ahora CNMC), la facturación del comercio electrónico aumentó un 24 '8\% interanual en el primer trimestre de $2017^{\mathrm{T}}$; el estudio Global Ecommerce Report 2017 preveía un crecimiento mundial de la facturación en comercio electrónico del $17 \%^{2}$, y la Unión Europea no ha podido quedarse al margen de esta situación, de modo que viene trabajando desde 2015 en la búsqueda de un Mercado Digital Único con el fin de conseguir un régimen jurídico común para todos los países miembro que genere una situación de seguridad jurídica en cuanto al comercio electrónico.

A pesar de los grandes beneficios que aporta esta proliferación del comercio electrónico tanto a empresarios como a consumidores, e incluso a los propios Estados, es necesario constatar que ha creado situaciones en las que resulta, como mínimo, complicado conocer el régimen jurídico aplicable 3 .

Cada día observamos la aparición de nuevas ideas, nuevos servicios y, en definitiva, nuevos usos del propio comercio electrónico y de internet en general, lo que hace difícil adaptar el derecho aplicable a cada nueva situación concreta. En este sentido, observamos cómo surgen nuevos medios de promoción o publicidad a través de la web que pueden comportar actos de competencia desleal, en concreto, hablaremos del falseamiento de los reputational feedback systems, o de la generación de opiniones falsas.

\section{Reputational Feedback System}

Uno de los puntos más negativos del comercio electrónico es que no tienes la posibilidad de inspeccionar el producto o servicio que vas a contratar de primera mano, no existe inmediación a la hora de contratar, de modo que el consumidor debe confiar en lo establecido en los apartados de la información precontractual existente en la plataforma de comercio electrónico (que en ocasiones es escasa). Por esta razón se implantó en el art. 68 TRLGDCU la posibilidad de que los consumidores pudieran desistir del contrato de forma injustificada en un periodo de I4 días desde el momento de contratación. Asimismo, esta es la razón por la que empezaron a generarse páginas web que permitieran calificar productos o servicios por parte de los usuarios, los llamados reputational feedback system.

\footnotetext{
${ }^{\mathrm{I}} \mathrm{CNMC}$, «El comercio electrónico supera en España los 6.700 millones de euros en el primer trimestre de 20I7, casi un 25\% más que el año anterior», en https://www.cnmc.es/node/365095.

${ }^{2}$ ECOMmerce Foundation, Global Ecommerce Report 2017, en http://www.ecommercefoundation.org/in-thenews/press-release-global-ecommerce-country-report-20I7.

${ }^{3}$ Sobre estas cuestiones es interesante leer el Blog especializado en Derecho Tecnológico, TicsLaw (vid. en http://ticslaw.es).
} 
Dada la importancia de la simple presencia de los empresarios en Internet, cobran también importancia dos conceptos relacionados, la denominada identidad digital corporativa, y la noción de reputación social o corporativa on-line":

- La identidad digital corporativa puede ser definida como el conjunto de información sobre una empresa expuesta en Internet (datos, imágenes, registros, noticias, comentarios, etc.) que conforma una descripción de dicha organización en el plano digital.

- Como es sabido, la reputación corporativa es el concepto que mide cuál es la valoración que hace el público de una compañía. Esta definición es trasladable al mundo de Internet y a la Web 2.0 donde aparece la idea de reputación digital corporativa.

De este modo, cada vez se está generalizando más la implantación en páginas web de secciones en las que los usuarios de la web puedan calificar la calidad del servicio prestado y de los productos comprados, de modo que los nuevos usuarios, antes de contratar pueda conocer la experiencia que han tenido otros usuarios, de modo que sirven para generar una reputación digital corporativa.

Estos sistemas se han extendido de tal manera que existe la posibilidad de puntuar los productos o servicios prestados por empresas que no tienen presencia digital, existiendo páginas web dedicadas exclusivamente a estos sistemas de reputación online 5 .

El objetivo de esta herramienta cada vez más extendida es la «recopilación de datos e informes de actividad para elaborar una clasificación de su actividad teniendo en cuenta el cumplimiento de estándares de diligencia profesional» ${ }^{6}$ con el fin de generar una reputación corporativa digital de la empresa.

Estos sistemas de calificación son extraordinariamente beneficiosos tanto para consumidores (pues les permite concebir de forma más clara el producto o servicio que van a recibir), como para las empresas (pues les permite conocer de primera mano la opinión de los consumidores ${ }^{7}$ con el fin de mejorar sus servicios, además de que afectan a su reputación como marca). Sin embargo, es posible que estos sistemas de reputación online

\footnotetext{
${ }^{4}$ MARTíneZ NADAL, A., «Publicación en páginas web de valoraciones falsas con incidencia en la reputación digital de los empresarios de alojamiento: ¿una práctica desleal?», en Revista de Derecho Mercantil, núm. $297 / 2015$.

${ }^{5}$ El ejemplo más claro de este tipo de páginas web es «Tripadvisor».

${ }^{6}$ García Montoro, L., «El futuro del Mercado Digital Único pasa por la regulación de las plataformas online», en Revista CESCO de Derecho de Consumo, 7.10.20I6.

${ }^{7}$ CAstillo, T., «Dos euros por review: Así se organiza en Facebook el negocio de las reviews compradas en Amazon» en www.xataka.com 06.08.20I8 (Disponible en: https://www.xataka.com/ecommerce/necesitamosreviews-amazon-asi-se-organiza-facebook-provechoso-negocio-opiniones-productos; fecha de consulta 09.0I.2019). Amazon responde sobre la existencia de grupos que «mercadean» con las opiniones de la siguiente forma: «las opiniones y valoraciones de usuarios son un elemento muy importante a la hora de dar visibilidad a productos dentro de nuestro catálogo». Por eso aseguran no tolerar el tipo de «prácticas abusivas» que surgen en estos grupos. «Pueden confundir y manipular las decisiones de otros clientes».
} 
sean mal utilizados, así, se han llegado a crear empresas cuyo servicio es generar comentarios y calificaciones falsas de modo masivo.

Esto supone que las empresas puedan falsear esta información con el fin de mejorar su posición en el mercado, ya sea generando comentarios positivos falsos relativos a sus propios productos o servicios; o generando comentarios negativos masivos de los productos y servicios de la competencia.

Además, debemos considerar también como actos de falseamiento de estas calificaciones o informes no sólo el generar comentarios falsos, como hemos dicho, sino también la eliminación por parte de la empresa de los comentarios negativos realizados por los usuarios; así como aquellas situaciones en que se desplazan los comentarios negativos al último lugar, dejando en las primeras posiciones únicamente los comentarios positivos, haciendo caso omiso a un criterio cronológico, que realmente sería más fiable para el destinatario de productos o servicios.

Asimismo, existen páginas web que establecen sistemas de reputación online falsos, en los que únicamente se observan comentarios positivos y que no permiten al destinatario real hacer ninguna clase de comentario.

\section{Falseamiento de reputational feedback system como actos de competencia desleal}

Internet resulta un medio propicio para la aparición de novedosos comportamientos desleales que encajan en alguno de los tipos de actos previstos en los artículos 5 y ss. LCD o en la cláusula general del artículo 4 LCD9 .

Como ya hemos dicho en el punto anterior, el falseamiento de los sistemas de calificación de productos y servicios es un hecho, pues el control que tienen las empresas sobre dichos comentarios no suele ser muy efectivo.

De este modo podríamos calificar este falseamiento de información como actos de competencia desleal.

Como ya sabemos, el art. 4 LCD establece que serán actos de competencia desleal todos aquellos que resulten objetivamente contrarios a la buena fe. Es claro que el comportamiento del que venimos tratando es un acto de competencia contrario a la buena fe, pues supone falsear la información de que disponen los usuarios a la hora de contratar un servicio o comprar un bien.

Sin embargo, además de poder insertar este comportamiento en los actos que contempla el art. 4 LCD como criterio general, podemos decir que este tipo de comportamiento se puede calificar como los actos de engaño del art. 5 LCD.

Respecto a los actos de engaño, «se considera desleal por engañosa cualquier conducta que contenga información falsa o información que, aun siendo veraz, por su contenido o presentación induzca o pueda inducir a error a los destinatarios, siendo susceptible de alterar su comportamiento económico (...)» (art. 5 LCD). No cabe duda, pues,

\footnotetext{
${ }^{8}$ AGUILAR, R., «Así es una granja de smartphones que hacen reviews falsas de apps», en www.andro4all.com I5.5.20I7 (Disponible en: https://andro4all.com/20I7/05/reviews-falsas-apps-play-store; fecha de consulta I6.5.20I7).

${ }^{9}$ De Miguel Asensio, P.M., Derecho Privado de Internet, Pamplona, Thomson Reuters Aranzadi, 2015.
} 
de que el falseamiento de la información introducida en los reputational feedback system son actos de engaño.

Asimismo, este falseamiento de información es relativo a las características principales de los bienes o servicios, como ya hemos dicho, por lo que estaríamos ante el supuesto concreto de actos de engaño del art. 5.I b) LCD.

Es innegable que los comportamientos de que estamos hablando contienen información falsa, siendo más dudoso el hecho de que puedan inducir al destinatario a un error capaz de alterar su comportamiento económico.

De este modo, habrá que estar al caso concreto para saber si este tipo de comportamiento puede generar tal error sobre el destinatario de los bienes o servicios, pues resulta difícil creer que, por ejemplo, un único comentario falso pueda alterar la conducta del usuario.

Además, podemos decir que estos actos de competencia desleal pueden ser frente a los competidores (especialmente en los supuestos en los que se introduce información falsa sobre los productos o servicios prestados por los competidores); y en todo caso frente a los consumidores, pues son los destinatarios directos de esta información falsa y quienes van a verse afectados por estos comentarios a la hora de contratar con una empresa $u$ otra, pues los consumidores comprarán los bienes o contratarán los servicios con mejores calificaciones, pues como hemos dicho supra la experiencia de usuarios anteriores es muy importante a la hora de generar expectativas en el comercio electrónico.

De hecho, podemos ver cómo una de las páginas web más importantes en materia de rating online en el sector de la hostelería, «TripAdvisor», fue multada por el organismo regulador de la competencia en Italia (AGCM, Autorità Garante della Concorrenza e del Mercato), que le impuso en diciembre de 2014 una multa de medio millón de euros por considerar que no aplicó los controles necesarios para evitar la publicación de calificaciones o comentarios falsos.

La resolución, de i9 de diciembre de 20I4, tiene su origen en la reclamación presentada por la Federazione delle Associazioni Italiane Alberghi e Turismo. El objeto de este procedimiento fue la práctica de difusión de información engañosa, en el sentido de que los instrumentos y procedimientos adoptados por la empresa no garantizaban la veracidad de las publicaciones al no ser estos suficientes para afrontar las valoraciones falsas.

La autoridad de la competencia italiana considera que TripAdvisor remarca en sus comunicaciones comerciales la veracidad y autenticidad de los comentarios existentes en su página web, precisando que los mismos son publicados por auténticos viajeros, suponiendo esta declaración por parte de TripAdvisor un papel central en la decisión de los consumidores para «orientar sus propias preferencias y elegir entre los servicios ofrecidos por los establecimientos presentes en su base de datos» ${ }^{\text {10 }}$.

Del mismo modo cabe destacar lo acontecido el i3 de septiembre de 2018 , en Italia donde el Tribunal Penal de Lecce, en la provincia del Salento, ha dictado una sentencia histórica al respecto. El propietario de PromoSalento, una empresa dedicada a la promoción

\footnotetext{
${ }^{\text {Io }}$ MARTíneZ NADAL, A., «Publicación...», op. cit.
} 
de la región ha sido multado con 8.000 euros de multa y a nueve meses de prisión por vender críticas ficticias de locales de hostelería, que posteriormente eran publicadas en Tripadvisor.

Por último, podríamos considerar en última instancia que este tipo de conductas pueden suponer un atentado contra el honor y la propia imagen de las empresas perjudicadas cuando se realicen falsos comentarios negativos, pues el propio TC ha considerado a las empresas como titulares de este derecho incluido en el art. I8 CE ${ }^{\mathrm{II}}$. De este modo, los empresarios podrían acudir para proteger su derecho al honor, intimidad y propia imagen a las siguientes normativas:

- Ley Orgánica I/I982, de 5 de mayo de Protección Civil del derecho al honor, la cual protege a las empresas frente a cualquier tipo de intromisiones ilegítimas que pudieran resultar perjudiciales para su reputación.

- Ley Orgánica 2/1984, de 26 de marzo, sobre el derecho de rectificación, la cual establece que toda persona, natural o jurídica, tiene derecho a rectificar la información difundida que considere inexacta y cuya divulgación pueda causarle perjuicio.

- Ley 34/2002, de in de julio de Servicios de la Sociedad de la Información y de Comercio Electrónico (en adelante LSSI), que regula el régimen de responsabilidad de los prestadores de servicios de la sociedad de la información (PSSI), permitiendo atribuirles responsabilidad civil por intromisiones al derecho al honor.

- Artículos 205 a 216 del Código penal, reguladores de los delitos contra el honor (calumnias e injurias).

\section{Control de los reputational feedback systems}

Como ya hemos dicho, actualmente esta herramienta utilizada por las plataformas digitales carece de un sistema de control homogéneo, dependiendo absolutamente de la voluntad y diligencia del propio empresario. Esto conlleva a que se generen dudas en cuanto a la veracidad de estas manifestaciones que otorgan prestigio a los empresarios, razón ésta por la que debemos valorar la regulación de estos reputational feedback systems para aumentar la confianza de los usuarios en las operaciones realizadas en línea, así como para evitar actos de competencia desleal como los arriba estudiados.

De este modo, el Research Group on the Law of Digital Services, en su borrador de propuesta de Directiva sobre plataformas de intermediarios online ${ }^{\mathrm{i2}}$, propone una regulación para estos sistemas de reputación en su artículo 8.

Así, esta propuesta establece una serie de estándares que deberán cumplir los reputational feedback systems para garantizar su fiabilidad, entre los que destacan:

- La necesidad de que los informes utilizados para elaborar la calificación se refieran a operaciones que se hayan realizado a través de la plataforma, con el fin de evitar que se generen comentarios positivos o negativos únicamente por razones de

\footnotetext{
${ }^{\text {II }}$ Vid. STC I39/1995.

I2 Research Group On The Law Of Digital Services, «Discussion Draft of a Directive on Online Intermediary Platforms», en EUCML Journal of European Consumer and Market Law.
} 
competencia, de modo que los comentarios y calificaciones se refieran exclusivamente a la experiencia real de los consumidores (art. 8.4 a).

- Que se indique si los informes se han realizado a cambio de cualquier contraprestación por parte de la plataforma (art. 8.4 b). Es frecuente que las plataformas soliciten a terceros expertos que realicen informes sobre el producto (reviews).

- Que los informes sean accesibles de forma cronológica y que exista acceso a dichos informes al menos durante un año desde su publicación (art. 8.4f).

- La existencia de un mecanismo de queja que permita a los usuarios poner en conocimiento de las plataformas la existencia de dudas acerca de la autenticidad de la calificación publicada.

Asimismo, la plataforma tiene la obligación de eliminar información engañosa que el proveedor haya facilitado siempre que: (I) un cliente le haya informado de que dicha información es engañosa; o (2) haya podido detectar dicho engaño mediante reputational feedback systems. De este modo, cuando conociendo dicha información no la elimine o rectifique, será esta quien responda de los daños ocasionados al cliente (art. I7).

\section{Conclusiones}

De la realización de este trabajo podemos extraer que los sistemas de reputación online son mecanismos realmente útiles tanto para los destinatarios de servicios y productos, como para los propios empresarios. Sin embargo, estos sistemas conllevan un gran peligro en el ámbito de la competencia, siendo muy fácil falsear los datos utilizados por empresas para valorar sus productos y servicios. De hecho, como hemos visto, ya se han dado casos en los que se ha sancionado a importantes empresas por no realizar un control suficiente para garantizar la veracidad de los informes y calificaciones realizados para cada producto.

Por otro lado, resulta bastante sencillo comprar reviews falsas en Internet, basta con realizar una búsqueda simple para que aparezcan las formas más fáciles y variadas para obtenerlos (ver ejemplos en Figura I).

Así, es necesario que se implemente un sistema de control uniforme para estos mecanismos que eleve el control de veracidad de los comentarios que realicen los destinatarios de productos y servicios. 


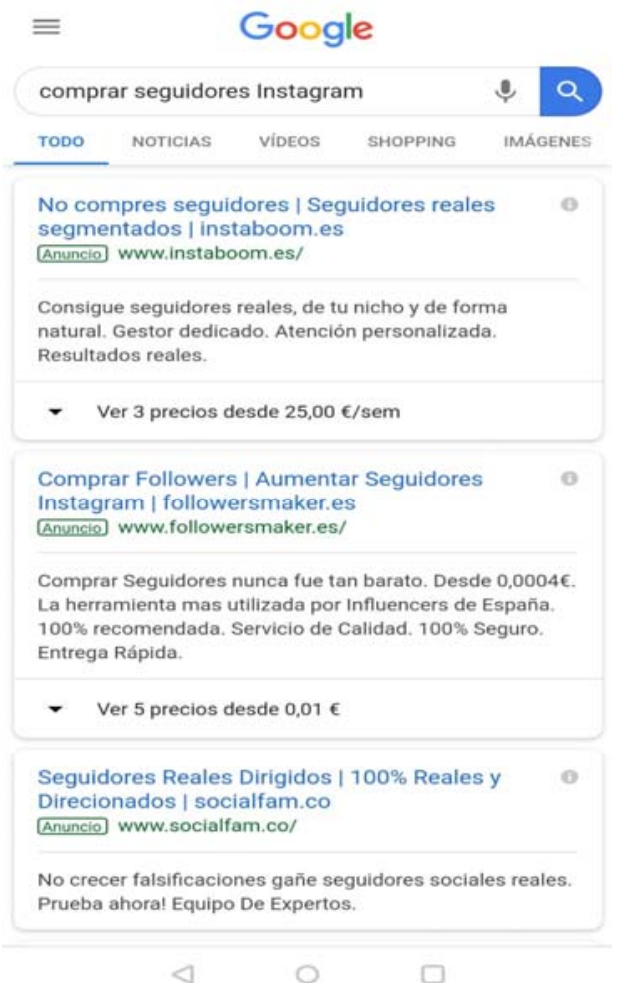

Google

\begin{tabular}{l} 
Q comprar reviews \\
TODO NOTICIAS IMÁGENES VIDEOS \\
Opiniones-Verificadas - Aumentar sus ... \\
https://www.opiniones-verificadas.com \\
de los usuarios consultan las opiniones de \\
clientes antes de comprar online. de las personas \\
que leen las opiniones consideran que ... \\
Visitaste esta página el 12/01/19. \\
Tarifas Solución Cl.opiniones-verificadas.col \\
\hline
\end{tabular}

TITANOBOX: Compra «Reseñas Positivas» en Google al mejor precio!

https://titanobox.com

Comentarios reales + Valoraciones positivas y de calidad + Reviews de (5) estrellas para optimizar la ficha de tu negocio en Google My ...

Visitaste esta página el 12/01/19.

Comprar reseñas Google | 5 Estrellas Para tu negocio. $100 \%$ Seguro

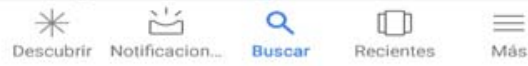

Figura I

\section{Bibliografía}

AgUilar, Ricardo, «Así es una granja de smartphones que hacen reviews falsas de apps», en www.andro4all.com 15.5.20I7 (Disponible en: https://andro4all.com/20I7/05/ reviews-falsasapps-play-store; fecha de consulta I6.5.20I7).

CASTILlo, Toni, «Dos euros por review: Así se organiza en Facebook el negocio de las reviews compradas en Amazon» en www.xataka.com 06.08.20I8 (Disponible en: https://www.xataka.com/ecommerce/necesitamos-reviews-amazon-asi-se-organiza-facebookprovechoso-negocio-opiniones-productos; fecha de consulta 09.01.2019)

CNMC, «El comercio electrónico supera en España los 6.700 millones de euros en el primer trimestre de 20I7, casi un $25 \%$ más que el año anterior», en https://www.cnmc.es/node/365095.

De Miguel Asensio, Pablo Miguel, Derecho Privado de Internet, Pamplona, Thomson Reuters Aranzadi, 2015

ECOMMERCE Foundation, Global Ecommerce Report 20I7, en http://www.ecommerce foundation.org/in-the-news/press-release-global-ecommerce-country-report-20I7.

GARCía Montoro, Lourdes, «El futuro del Mercado Digital Único pasa por la regulación de las plataformas online», en Revista CESCO de Derecho de Consumo, 7.10.20I6.

MARTÍNEZ NADAL, Apol-lònia, «Publicación en páginas web de valoraciones falsas con incidencia en la reputación digital de los empresarios de alojamiento: ¿una práctica desleal?», en Revista de Derecho Mercantil, núm. 297/20I5

Research Group On The Law Of Digital Services, «Discussion Draft of a Directive on Online Intermediary Platforms», en EUCML Journal of European Consumer and Market Law. 